\title{
Preterm neonates with patent ductus arteriosus
}

\author{
Nelson Itiro Miyague *
}

\begin{abstract}
$T_{\text {he }}$ connects the pulmonary artery to the aorta in the fetus. It has great importance during that stage of life because the majority of the combined ventricular output passes through this communication to the descending aorta and the placenta. This is because of the greater volume ejected by the right ventricle and the small amount of blood that is sent to the lungs. This
\end{abstract} blood contains lower oxygen pressure than in the aorta. ${ }^{1}$

Functional closure of the ductus arteriosus in full term newborns takes place at around 12 to 15 hours postpartum and is permanent at around 5 to 7 days, although in some cases it can take until the 21 st day. In premature infants the ductus arteriosus remains open for a longer time and the frequency of patent ductus arteriosus increases in proportion to the degree of immaturity. Afiune et al., ${ }^{2}$ publish an article in this issue confirming that these figures reach a frequency of $58.8 \%$ in newborn born weighing less than $1,000 \mathrm{~g}$ and of $25 \%$ among those weighing more than $1,000 \mathrm{~g}$. The mechanism by which the duct is kept open remains unknown, although the high concentrations of prostaglandin E2 found in premature infants and the ineffective initial closure are some of the factors responsible for this response. ${ }^{1,3}$

Symptomatic patent ductus arteriosus is defined by the presence of heart murmur, tachycardia, hyperactive precordium and increase in the amplitude of the pulse. These criteria do not, however, offer good correlation with hemodynamic repercussions during the first days of life, which is determined by the quantity of blood diverted to the left through the ductus arteriosus. ${ }^{4}$ Additionally, clinical status varies with the newborn's gestational age.

In common with clinical examination, electrocardiogram and chest $x$-ray also have little effectiveness for diagnosis and quantification of hemodynamic repercussions. For these

* Full professor, Pontifícia Universidade Católica do Paraná (PUC-PR). Professor, Universidade Federal do Paraná (UFPR), Curitiba, PR, Brazil.

Suggested citation: Miyague NI. Preterm neonates with patent ductus arteriosus. J Pediatr (Rio J). 2005;81:429-30. reasons, echocardiograms have a primary role in management and diagnosis of ductus arteriosus in preterm newborns, as Afiune et al demonstrate. ${ }^{2}$ They observed murmur in $18 \%$, precordial impulses in $13.1 \%$ and increased pulse pressure in $3.3 \%$ of patent ductus arteriosus cases that were confirmed by echocardiogram. These signs were more common patients with larger arterial ducts, but, even so, $28.5 \%$ of these did not present any of these signs.

Echocardiographic measurements such as left atrium diameter, ratio of left atrium to aorta diameter, ductus arteriosus diameter, flow pattern in the descending aorta and the left branch of the pulmonary artery, have been employed to quantify the ductus arteriosus. ${ }^{5}$ Such quantification is highly important to treatment decisions and for diagnosis, since in the majority of cases clinical status is superimposed on pulmonary involvement. Differentiating the predominance between hemodynamic repercussions and the severity of lung damage is becomes more difficult the more premature the patient is. Nevertheless, mortality is directly related to ducts with hemodynamic repercussions. ${ }^{6}$

When the ductus arteriosus has hemodynamic repercussions, significant complications can also result. The presence of a patent ductus arteriosus in low birth weight preterms is an independent risk factor for developing necrotizing enteritis. ${ }^{7}$ The prevention of prematurity and clinically significant closure of the ductus arteriosus have been demonstrated to be strong evidence in favor of reducing the occurrence of bronchopulmonary dysplasia. ${ }^{8}$ Ductus arteriosus closure also reduces the risk of pulmonary hemorrhage. ${ }^{1}$ This last complication was the cause of three deaths in the series reported on by Afiune et al., ${ }^{2}$ and all had been diagnosed with hyaline membrane disease and had been given exogenous surfactant on the first day of life. In a recent systematic review of cerebellar hemorrhage, a complication which is being diagnosed more often as neuroimaging improves, an association was observed between the complication and patent ductus arteriosus. ${ }^{9}$

With current treatment, whether medical or surgical, the prognosis of these patients has significantly improved. 
There are no published data that indicate which of the two treatments should be employed for symptomatic ductus arteriosus. ${ }^{10}$

Indomethacin provokes closure in a large majority of cases, but research has shown that in up to $40 \%$ of cases it may be ineffective. There may be reopening in up to $35 \%$ of cases that initially respond to the drug. There is no longer consensus in the literature that the use of the drug should be prolonged to avoid reopening. The procedure reduces the risk of intracranial hemorrhage and renal dysfunction, but appears to increase the risk of chronic lung disease. ${ }^{11}$

Ibuprofen has also been used for treating the anomaly. In terms of efficacy the results are similar to indomethacin, but it appears to increase the risk of chronic lung disease and pulmonary hypertension. ${ }^{12}$

The use of indomethacin as a prophylactic treatment reduces the number of symptomatic ductus arteriosus cases, the need for surgery and cases of severe intraventricular hemorrhage. There is no evidence on the beneficence or maleficence of later results including with relation to neurological development. ${ }^{13}$

Surgical mortality is extremely low nowadays, but complications such as pneumothorax and increased degree II and IV retinopathy of prematurity incidence rates have been described. With this treatment the risk of death on duct closure has significantly reduced. ${ }^{10}$

More important than what type of treatment should be adopted is recognizing which patients need treatment. This fundamental, since ductus arteriosus, even symptomatic, can progress to spontaneous closure. On the other hand, current treatments are not entirely riskfree. This being so, the work done by Afiune et al. ${ }^{2}$ can help with the decision on how to proceed with a preterm newborn with ductus arteriosus, since it demonstrates a simple and reproducible method for identifying in advance those patients who require treatment and those who will achieve spontaneous closure.

\section{References}

1. Rudolph AM. The ductus arteriosus and persistent patency of the ductus arteriosus. In: Rudolph AM, editor. Congenital Diseases of the Heart: Clinical-Physiological Considerations. Armonk (NY): Futura Publishing Company; 2001. p. 155-196.

2. Afiune JY, Singer JM, Leone CR. Evolução ecocardiográfica de recém-nascidos com persistência do canal arterial. J Pediatr (Rio J). 2005;81:454-60.

3. Clyman RI, Goetzman BW, Chen YQ, Mauray F, Kramer RH, Pytela $R$, et al. Changes in endothelial cell and smooth muscle cell integrin expression during closure of the ductus arteriosus: an immunohistochemical comparison of the fetal, preterm newborn, and full-term newborn rhesus monkey ductus. Pediatr Res. 1996;40:198-280.

4. Alagarsamy S, Chhabra M, Gudavalli M, Nadroo AM, Sutija VG, Yugrakh D. Comparison of clinical criteria with echocardiographic findings in diagnosing PDA in preterm infants. J Perinat Med. 2005;33:161-4.

5. El Hajjar M, Vaksmann G, Rakza T, Kongolo G, Storme L. Severity of the ductal shunt: a comparison of different markers. Arch Dis Child Fetal Neonatal Ed. 2005;90:F419-22.

6. Brooks JM, Travadi JN, Patole SK, Doherty DA, Simmer K. Is surgical ligation of patent ductus arteriosus necessary? The Western Australian experience of conservative management. Arch Dis Child Fetal Neonatal Ed. 2005;90:F235-90.

7. Dollberg S, Lusky A, Reichman B. Patent ductus arteriosus, indomethacin and necrotizing enterocolitis in very low birth weight infants: a population-based study. J Pediatr Gastroenterol Nutr. 2005;40:184-8.

8. D'Angio CT, Maniscalco WM. Bronchopulmonary dysplasia in preterm infants: pathophysiology and management strategies. Paediatr Drugs. 2004;6:303-30.

9. Limperopoulos C, Benson CB, Bassan H, Disalvo DN, Kinnamon DD, Moore $M$, et al. Cerebellar hemorrhage in the preterm infant: ultrasonographic findings and risk factors. Pediatrics. 2005;116:717-24.

10. Malviya M, Ohlsson A, Shah S. Surgical versus medical treatment with cyclooxygenase inhibitors for symptomatic patent ductus arteriosus in preterm infants (Cochrane Review). In: The Cochrane Library, Issue 3, 2005. Chichester, UK: John Wiley \& Sons, Ltd.; 2005.

11. Herrera C, Holberton J, Davis P. Prolonged versus short course of indomethacin for the treatment of patent ductus arteriosus in preterm infants (Cochrane Review). In: The Cochrane Library, Issue 3, 2005. Chichester, UK: John Wiley \& Sons, Ltd. ; 2005.

12. Ohlsson A, Walia R, Shah S. Ibuprofen for the treatment of patent ductus arteriosus in preterm and/or low birth weight infants (Cochrane Review). In: The Cochrane Library, Issue 3, 2005. Chichester, UK: John Wiley \& Sons, Ltd.; 2005.

13. Fowlie PW, Davis PG. Prophylactic intravenous indomethacin for preventing mortality and morbidity in preterm infants (Cochrane Review). In: The Cochrane Library, Issue 3, 2005. Chichester, UK: John Wiley \& Sons, Ltd.; 2005. 